\title{
Os Efeitos no Empacotamento de Peças Injetadas para Diferentes Espessuras de Canais de Ataque (Gate) Tipo Filme
}

\author{
Altair Carlos da Cruz ${ }^{1}$, Ricardo Pedro Bom ${ }^{2}$ \\ ${ }^{1}$ Universidade do Estado de Santa Catarina - UDESC. Professor da Faculdade de Tecnologia Senai. \\ e-mail: altair@joinville.senai.br \\ ${ }^{2}$ Universidade do Estado de Santa Catarina - UDESC. Professor do Centro de Ciências Tecnológicas. \\ e-mail: dem2rpb@joinville.udesc.br
}

\begin{abstract}
RESUMO
Este trabalho tem como objetivo determinar a variação da massa de corpos de prova fabricados pelo processo de moldagem por injeção. A partir de equações que tratam da solidificação de placas, foi correlacionado o tempo de solidificação do canal de ataque com o tempo de início de estabilização da massa do corpo de prova obtido na cavidade do molde de injeção. Para o desenvolvimento experimental foi utilizado o copolímero estireno-acrilonitrila (SAN). Para a realização dos corpos de prova, foi necessário secar o material, fixar alguns parâmetros de processo, tais como pressão de injeção, tempo de injeção, temperatura nos diferentes estágios e temperatura do molde. Os parâmetros variáveis foram o tempo e a pressão de recalque. Com os corpos de prova prontos, suas massas foram determinadas, inicialmente, para o conjunto corpo de prova e canais de distribuição; em seguida, para o corpo de prova individualmente, sendo este previamente separado dos canais de distribuição.

A variação da massa dos corpos de prova para as diferentes pressões de recalque e seus respectivos desvios-padrão foram representadas graficamente em função da variação do tempo de recalque.

A massa do corpo de prova começou a estabilizar a partir de um certo tempo. Este tempo foi determinado graficamente e ficou coerente com os resultados dos tempos calculados a partir de equações que tratam do resfriamento de placas.
\end{abstract}

Palavras-chave: Termoplástico, solidificação, massa injetada, PvT.

\section{The Effects of Injection Molding Packing for Different Thickness of Film Type Gates}

\section{ABSTRACT}

The aim of his study is to determine the model test bulk used by the injection molding process. The mathematical model governing by the plate solidification will indicate the solidification time of the gate together with the beginning of the stabilization of the cavity bulk. In this test a styrene-acrylonitrile copolymer (SAN) will be used. In order to develop the model tests, the material had to be dried to establish some parameters like: injection pressure, injection time, temperature of the different stages as well as moulding temperature. The variable parameters were the time and the discharge pressure. As the model tests were fully develoved, bulks were determined, first for the mould cavity and branches and next for the single cavity which was separated from the branches. The variation of the cavity bulk for the different discharge pressures and the standard deviation were graphically represented due to the time deviation of the discharge. The results showed that the time the bulk cavity begins to stabilize matches the calculated time, for the nonflow temperature, as well as the glass part temperature, the discharge pressure.

Keywords: Thermoplastical, solidification, injection bulk, PvT.

\section{INTRODUÇÃO}

Canais de distribuição e de ataque (gate) podem ser feitos de várias formas e requerem cuidados e considerações especiais para cada moldagem específica. Algumas formas de canais de ataque são especiais e são adotadas para servir a moldagens particulares, entretanto, são variações das formas básicas. É útil consultar a literatura dos fabricantes para conhecer melhor sobre os detalhes dos pontos de injeção e sobre o material específico para a moldagem, de acordo com a característica do processo desejado [1-7]]. 
O processo de moldagem por injeção é um dos mais importantes processos industriais, sendo largamente empregado na fabricação de peças plásticas.

Diante de todas as variáveis possíveis, para a execução e o bom funcionamento de um molde de injeção, a forma e a localização do canal de ataque tem sido um ponto de extrema relevância nos projetos de molde de injeção, por estar diretamente ligado à quantidade e à vazão da massa recebida na cavidade e em função do tempo de solidificação desse canal [7].

A localização ideal é o mais próximo possível do centro da peça, a fim de minimizar as distâncias que o material deve percorrer para encher a cavidade. Quando o projeto da peça ou produto impedir este posicionamento, deve-se utilizar uma entrada maior, ou várias entradas por cavidade, permitindo um enchimento mais rápido [7].

Tendo ciência dessa complexidade no dimensionamento do canal de ataque, o presente trabalho apresenta um estudo abordando a variação da massa nos corpos de prova em função da espessura do canal de ataque e dos parâmetros de processos $[\underline{8}, \underline{9}]$. O aumento da massa nas cavidades até o final da fase de injeção é proporcional ao volume preenchido da cavidade [9]. Após a fase de injeção, o aumento da massa depende do tempo e da pressão recalque, da temperatura de injeção e do molde $[\underline{10}, \underline{11}]$.

\section{MATERIAIS E MÉTODOS}

O material utilizado neste trabalho foi o termoplástico copolímero de estireno acrilonitrila (SAN) tipo LURAN $358 \mathrm{~N}$ da BASF S.A., que apresenta alta resistência mecânica, dureza e estabilidade de forma ao aquecimento, além da alta transparência, com índice de fluidez entre 21,9 e $23,1 \mathrm{~cm}^{3} / 10 \mathrm{~min}$, e secado por 2 horas à $80^{\circ} \mathrm{C}$.

A injetora utilizada para este experimento foi a injetora da marca Battenfeld, modelo 250 Plus, com rosca de $22 \mathrm{~mm}$ de diâmetro e capacidade de injeção de $27 \mathrm{~g}$ de PE.

O corpo de prova tem a forma como indicado pela Figura 1. No porta-molde foram usinadas duas cavidades semelhantes e paralelas na mesma placa, porém, a diferença está na espessura do canal de ataque. Um dispositivo permitiu escolher a cavidade a ser injetada. Os efeitos da largura do canal de ataque foram considerados desprezíveis frente à espessura do mesmo. A cavidade é composta pelo canal principal, canal de distribuição, canal de ataque e corpo de prova.

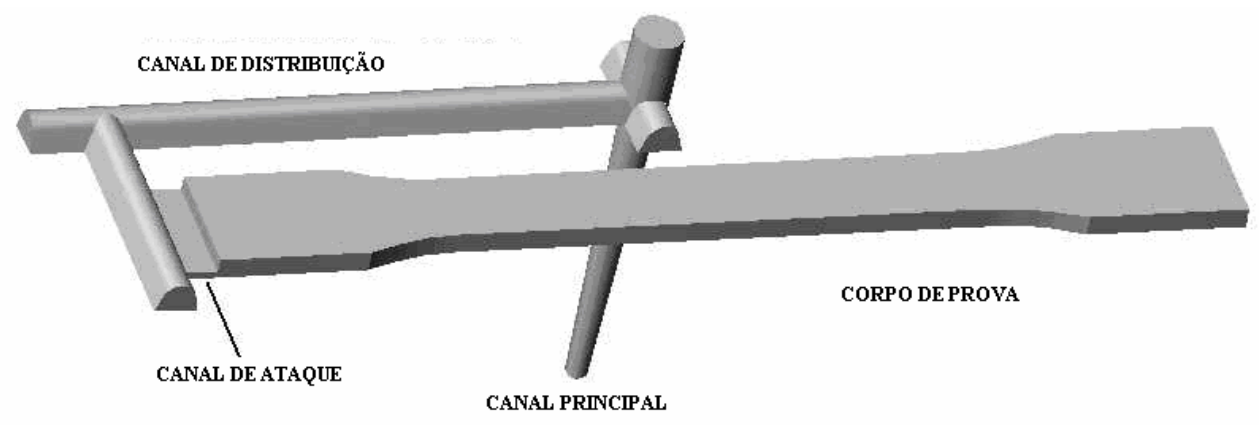

Figura 1: Corpo de prova e seus respectivos canais.

Os corpos de prova foram injetados com os seguintes parâmetros de processo: tempo de injeção de $5,5 \mathrm{~s}$; pressão de injeção de $33 \%$, correspondente a $53,7 \mathrm{MPa}$; velocidade de injeção de $17 \%$, correspondente a $9,3 \mathrm{~cm} / \mathrm{seg}$; temperatura de injeção de $230^{\circ} \mathrm{C}$ e temperatura na superfície do molde de $52 \pm 2{ }^{\circ} \mathrm{C}$ e uma temperatura ambiente de $25^{\circ} \mathrm{C}$.

Para a realização deste experimento foram injetados aproximadamente 1.000 corpos de prova. Como as espessuras dos canais de ataque são diferentes, estas cavidades foram identificadas como sendo: Caso 1, para o canal com espessura de 1,088 $\mathrm{mm}$ e Caso 2, para o canal com espessura de 2,202 $\mathrm{mm}$. Em ambos os casos o Corpo de provas tem $3 \mathrm{~mm}$ de espessura.

Depois de realizado o processo de injeção dos corpos de prova, foi determinada a massa total do conjunto (corpo de prova + canais) através de uma balança digital com precisão e com divisão de escala na ordem de $1.10^{-4} \mathrm{~g}$. Após a pesagem, foi realizado o processo de corte, separando os canais do corpo de prova $[7,8]$. Para a realização do corte foi utilizada uma serra de fita com um dispositivo adaptado para esta finalidade, o qual permitiu uma repetibilidade nas dimensões das peças cortadas [7]. 


\section{RESULTADOS}

Um dos parâmetros essenciais para o processo de moldagem por injeção é o tempo da fase de injeção $(\mathrm{t})$ e o tempo da fase de recalque, necessários para que a cavidade que corresponde ao corpo de prova seja preenchida e compactada. Correlacionado a este tempo está a velocidade (V), a vazão (Q), a temperatura de injeção e do molde $(\mathrm{T})$ e a pressão $(\mathrm{P})$ de injeção. O tempo de resfriamento também pode influenciar no processo.

Os resultados que serão mostrados a seguir foram obtidos a partir dos experimentos e demonstram uma forte dependência dos parâmetros de processo, tais como pressão e tempo de recalque do material durante a fase de recalque.

No primeiro momento, a fase de injeção foi realizada para os dois casos, sem a pressão e o tempo de recalque; desta forma determinou-se a massa inicial do conjunto e do corpo de prova. A fase de injeção termina no exato momento em que a última região da cavidade correspondente ao corpo de prova for preenchida. Em seguida, inicia a fase de recalque; nesta fase, dois parâmetros podem ser ajustados: a pressão e o tempo de recalque.

$\mathrm{Na}$ Figura 2 está representada a variação da massa do corpo de prova $(\mathrm{g})$ em função do tempo de recalque (s) para o Caso 1. Após a pesagem dos corpos de prova, foram determinadas as médias das massas de cinco corpos de prova e seus respectivos desvios-padrão, antes e depois do processo de recalque. Portanto, o ponto inicial da curva apresentada é sem recalque. Para os tempos de recalque a uma pressão de recalque de $10 \%$ e $20 \%$, a massa do corpo de prova apresenta uma oscilação. As médias das massas são, às vezes, inferiores a média da massa inicial determinada na fase de injeção, provavelmente devido à baixa pressão de recalque utilizada na máquina injetora. Quanto às pressões de recalque de 33\% e 40\%, tiveram um acréscimo de massa até aproximadamente 2,0 segundos. A partir deste tempo, a massa do corpo de prova estabilizou. Pode-se concluir que o canal de ataque se solidificou após o tempo de recalque de aproximadamente 2,0 segundos, visto que o corpo de prova não recebeu mais massa após esse tempo de recalque. A estabilização do acréscimo de massa pode ser observada graficamente para as pressões de recalque acima de $33 \%$. Entretanto, para os dois primeiros segundos de recalque, a variação de massa do corpo de prova depende tanto da pressão quanto do tempo de recalque. Pode-se observar ainda, nesta figura, que quanto maior a pressão, maior é a quantidade de massa injetada no corpo de prova e mais rápida é a taxa de incremento de massa.

Na Figura 2, a região sombreada representa o intervalo de tempo onde provavelmente teve início de estabilização da massa. No início desta região, ponto "a", o material deve ter atingido a temperatura de nãofluxo. Entende-se por temperatura de não-fluxo a temperatura na qual o material plastificado apresenta alta viscosidade e efetivamente não se pode mais ter um fluxo, devido à necessidade de altas pressões para pequenas vazões, o que limita a maioria dos equipamentos. No final da região sombreada , ponto "b", provavelmente ocorreu a solidificação do canal de ataque, o material atingiu a Tg. Com isso, não ocorrerá mais o aumento da massa do corpo de prova.

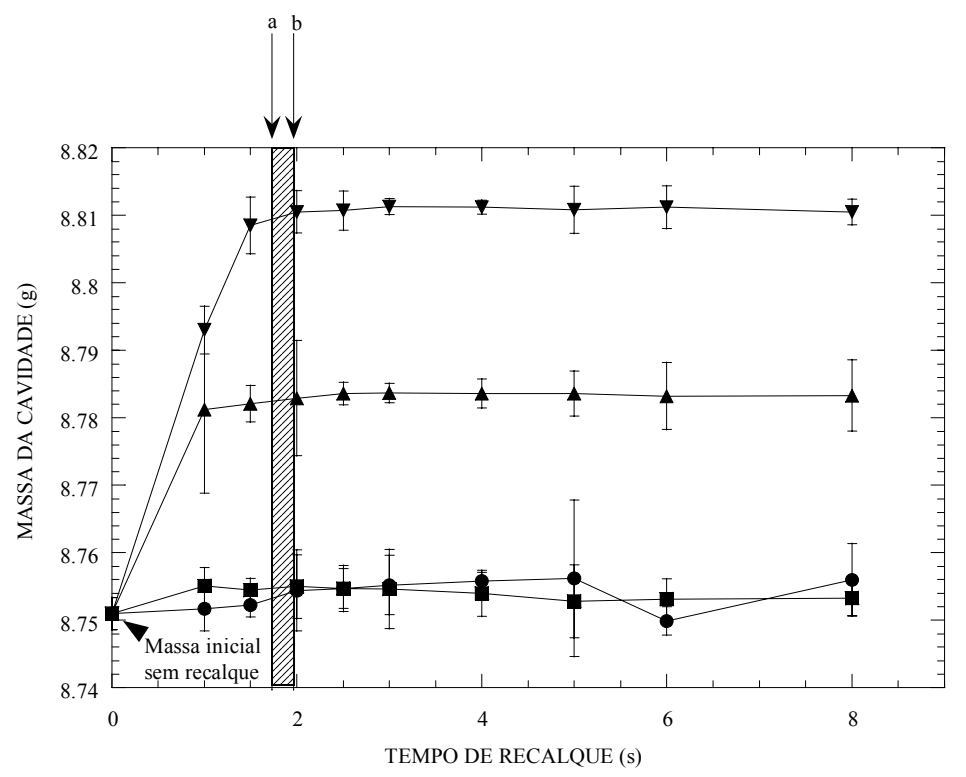

Figura 2: Massa do corpo de prova em função da variação do tempo de recalque para as pressões de recalque

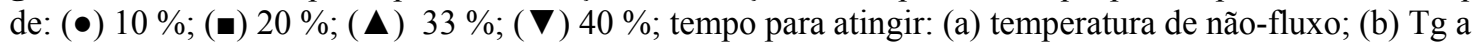
$\mathrm{P}=64,8 \mathrm{MPa}$. 
No Caso 2, além das pressões de recalque utilizadas no Caso 1, o experimento foi realizado também com uma pressão de recalque de $60 \%$, porém, somente para os tempos de 1 e 2 segundos, em virtude do surgimento de rebarbas nos corpos de prova para tempos superiores ou pressões maiores.

$\mathrm{Na}$ Figura 3 está representada a variação de massa do corpo de prova em função do tempo de recalque para as pressões de recalque utilizadas. Pode-se observar que houve um aumento significativo de massa dos corpos de prova para a pressão de recalque de $60 \%$ até o tempo de 2 segundos, entretanto, para as demais pressões de recalque, o aumento de massa do corpo de prova é bastante expressivo, até aproximadamente o tempo de recalque de 7,0 segundos. Após esse tempo, a massa do corpo de prova tende a estabilizar.

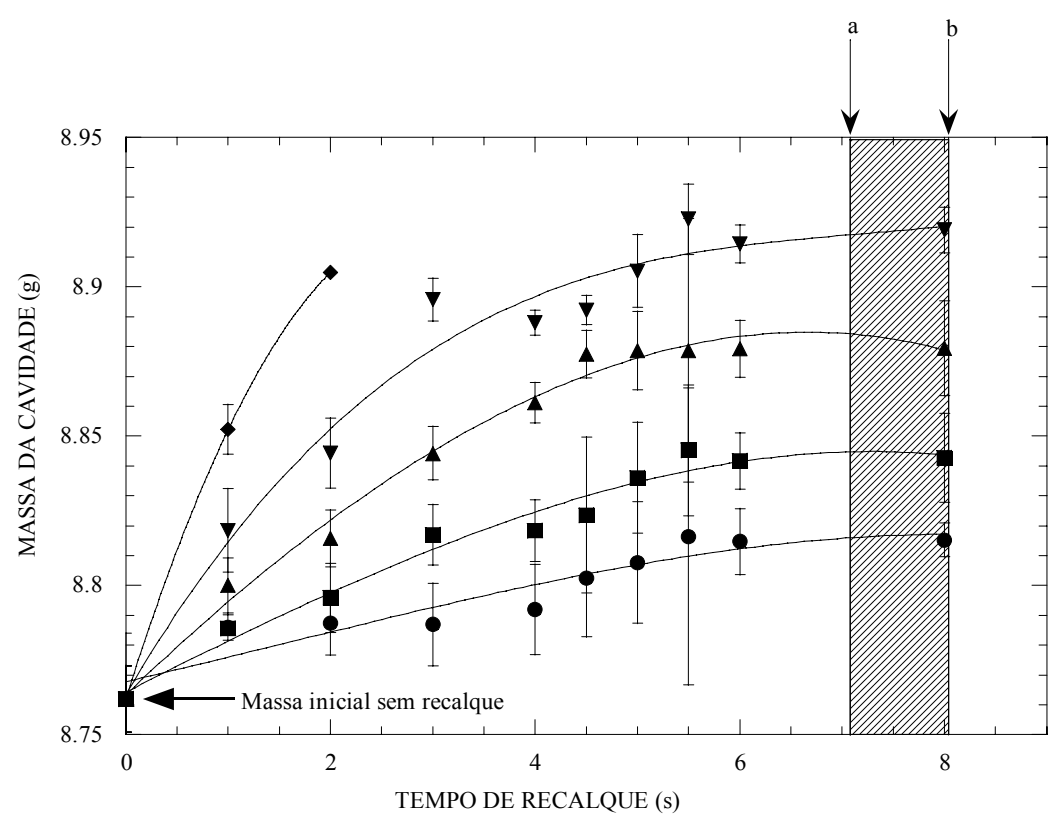

Figura 3: Massa do corpo de provas em função da variação do tempo de recalque para as pressões de

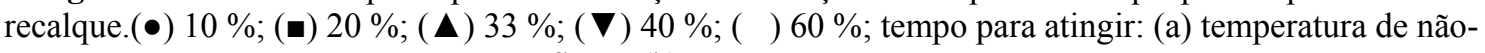
fluxo; (b) $\mathrm{Tg}$ a $\mathrm{P}=64,8 \mathrm{MPa}$

O tempo de solidificação do canal de ataque (gate) é um parâmetro importante para a tecnologia de moldagem por injeção visto que, se for muito fino o canal de ataque, não permite compactar o material na cavidade de interesse. Se for muito espesso, aumenta-se a compactação do material. Assim, para os Casos 1 e 2 , os tempos de solidificação dos canais de ataque foram diferentes, devido às espessuras diferentes dos mesmos.

A área sombreada da Figura 3 tem o mesmo significado dado na Figura 2, entretanto, o tempo para atingir a estabilização da massa do corpo de prova é maior, entre 7e 8 segundos.

Na Figura 4 foi determinado o caminho de resfriamento do material injetado a partir das curvas $\mathrm{P} v \mathrm{~T}$, utilizando a Equação 3.

Conforme os parâmetros obtidos na biblioteca do aplicativo Moldflow MPI 4.0 e utilizando a Equação 1, pode-se determinar o volume específico em função da variação da pressão e da temperatura.

$$
v(T, P)=V_{0}(T)\left[1-C \ln \left(1+\frac{P}{B(T)}\right)\right]+V_{t}(T, P)
$$

Onde $v(\mathrm{~T}, \mathrm{P})$ é o volume específico a temperatura $(\mathrm{T})$ e pressão $(\mathrm{P}) ; \mathrm{V}_{0}$ é o volume específico a pressão zero $\left(\mathrm{m}^{3} / \mathrm{kg}\right) ; \mathrm{T}$ é a temperatura em Kelvin $(\mathrm{K}) ; \mathrm{P}$ é a pressão em Pascal $(\mathrm{Pa})$; $\mathrm{C}$ é uma constante igual a 0,$0894 ; \mathrm{B}(\mathrm{T})$ é para a sensibilidade à pressão do material, $\mathrm{V}_{\mathrm{t}}(\mathrm{T}, \mathrm{P})$ é o volume específico para materiais cristalinos.

Por ser amorfo o material em estudo, não foi utilizada a parcela $\mathrm{V}_{\mathrm{t}}(\mathrm{T}, \mathrm{P})$ na Equação 1, em função de os coeficientes utilizados serem específicos para materiais cristalinos. 
No processo de moldagem por injeção foi utilizada uma pressão na fase de injeção de $53,7 \mathrm{MPa}$, (ver ponto A.) Terminada a fase de injeção, o equipamento entra com a pressão de recalque, neste caso superior à pressão de injeção e igual a $64,8 \mathrm{MPa}$ (ver ponto $\mathbf{B}$ da figura.) Desprezando a variação térmica durante a fase de recalque, o ponto $\mathbf{B}$ está logo abaixo do ponto $\mathbf{A}$. Em seguida, à medida que o material começa a resfriar, o volume específico vai diminuindo conforme a figura abaixo (ver os pontos $\mathbf{a} ; \mathbf{b} ; \mathbf{c}$ e d.) Do ponto B para o ponto a ou b é necessário um certo tempo de resfriamento. Porém, se a pressão de recalque cessar, a pressão do moldado irá diminuir e o volume específico tomará outro caminho, em direção ao ponto $\mathbf{C}$ e depois em direção a $\mathbf{D}$. Se a pressão de recalque for mantida por um período suficientemente grande, o material resfriará e solidificará na pressão de recalque. Com isso, o caminho de solidificação passará pelos pontos c e d. Deve-se notar, nas curvas $\mathrm{P} v \mathrm{~T}$, que para cada curva existe uma temperatura de transição vítrea $\mathrm{Tg}$, sendo que a esta temperatura o material encontra-se solidificado. Graficamente determinamos o valor de $\mathrm{Tg}$ como sendo igual a $120^{\circ} \mathrm{C}$ para as condições deste processo. Neste caso, mantendo-se a pressão de $64,8 \mathrm{MPa}$ quando a temperatura atingir $120^{\circ} \mathrm{C}$, o material praticamente passará para a fase sólida, porém existem grande quantidade de moléculas com mobilidade segmental de longo alcance inerente ao estado líquido. Tem-se, então, o resfriamento e a contração do material na fase sólida (ver caminho (d, D)) com a respectiva mudança de inclinação da reta, pois a partir deste ponto não há mais a necessidade de se recalcar o material $\mathrm{O}$ moldado convergirá para a pressão nula e à temperatura ambiente (ponto D); no caminho (d, D) ocorre a contração do material já no estado sólido.

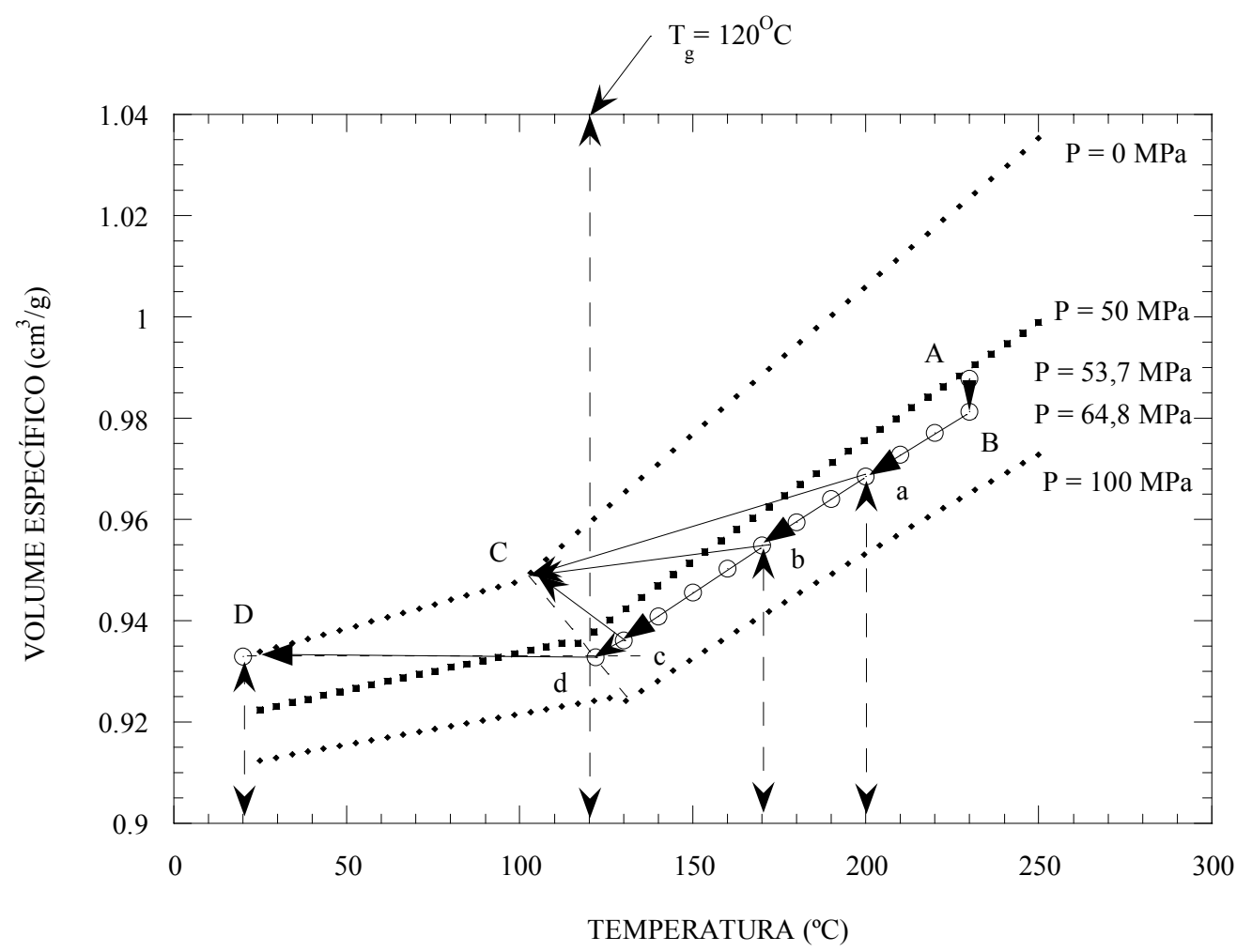

Figura 4: Volume específico vs temperatura em função da pressão, caminho de solidificação do material injetado. [7]

Quando se trabalha com exemplos reais, não se pode considerar o meio como infinito [10]. Assim, a solução do problema do resfriamento de placas pode ser tratado a partir da Equação 2. Esta equação tem os seguintes parâmetros: difusividade térmica $(\alpha)$, tempo de resfriamento $(t)$, espessura da placa (e), Distância do centro da placa até a superfície $(x)$, Temperatura do molde $\left(T_{m}\right)$, Temperatura de injeção $\left(T_{i}\right) \mathrm{e}$ Temperatura $(T)$. A solução desta equação é dada pela soma de um grande número de termos da série, sendo a sua convergência muito rápida. Para obter valores significativos neste trabalho foram utilizados menos de 20 termos. Uma solução aproximada da Equação 2 está representada pela Equação 3, utilizando somente o primeiro termo $(\mathrm{n}=0)$.

Para valores de $\left(\alpha t / e^{2}\right)$, superiores a 0,1 , a solução aproximada é efetivamente muito próxima da solução exata. Para valores inferiores, a solução aproximada não tem sentido, pois a mesma diverge 
fortemente quando o tempo de resfriamento tende a ser nulo. Esta divergência é inerente à solução analítica da equação exponencial.

$$
\begin{aligned}
& \frac{T_{m}-T}{T_{m}-T_{i}}=2 \sum_{n=0}^{\infty} \frac{(-1)^{n}}{\left(n+\frac{1}{2}\right) \cdot \pi} \exp \left[-\left(n+\frac{1}{2}\right)^{2} \pi^{2} \frac{\alpha \cdot t}{e^{2}}\right] \cos \left[\left(n+\frac{1}{2}\right) \frac{\pi \cdot x}{e}\right] \\
& t=-\frac{4 e^{2}}{\pi^{2} \alpha} \ln \left[\frac{\pi}{4}\left(\frac{T_{m}-T}{T_{m}-T_{i}}\right)\right]
\end{aligned}
$$

A solução da Equação 2 para os casos 1 e 2 e considerando a difusividade térmica $(\alpha)$ constante, está representada na Figura 5, pelas curvas contínuas.

A solução da Equação 3 para os casos 1 e 2 e considerando a difusividade térmica $(\alpha)$ dependente da temperatura está indicada também na Figura 5, pelas curvas tracejadas. Nesta figura estão indicadas cinco temperaturas, sendo a primeira de $52^{\circ} \mathrm{C}$, que é a temperatura do molde; a segunda de $101^{\circ} \mathrm{C}$, refere-se à temperatura de transição vítrea $(\mathrm{Tg})$ do material à pressão nula. A terceira, a $120^{\circ} \mathrm{C}$, foi obtida a partir das curvas PvT, que descreve o caminho de solidificação do material (ver Figura 4.) A quarta temperatura, de $130^{\circ} \mathrm{C}$, é a temperatura de não-fluxo do material [11]. A quinta temperatura, de $230^{\circ} \mathrm{C}$, é a temperatura na qual o material foi injetado.

Tomando a temperatura de não-fluxo como referência para o Caso 1, a partir de aproximadamente $1,74 \mathrm{~s}$ não haverá mais acréscimo de massa no corpo de prova. Comparando com o resultado experimental, Figura 1, este valor é coerente e está dentro da área sombreada. Para o Caso 2, o tempo seria de 7,10s, e comparando com a Figura 2, pode-se observar que este tempo se encontra dentro de uma faixa, a qual é bem provável que apresenta o início da estabilização da massa.

Utilizando a temperatura de transição vítrea para a pressão de $64,8 \mathrm{MPa}$, o tempo de solidificação para o Caso 1 foi de 1,98s para a Equação 3, e 1,97s para a Equação 2. Para o caso 2, o tempo de solidificação foi de 8,08s, para a Equação 3, e 8,04 s para a Equação 2 - valores que estão dentro das variações experimentais e encontram-se dentro da região sombreada nas Figuras 2 e 3.

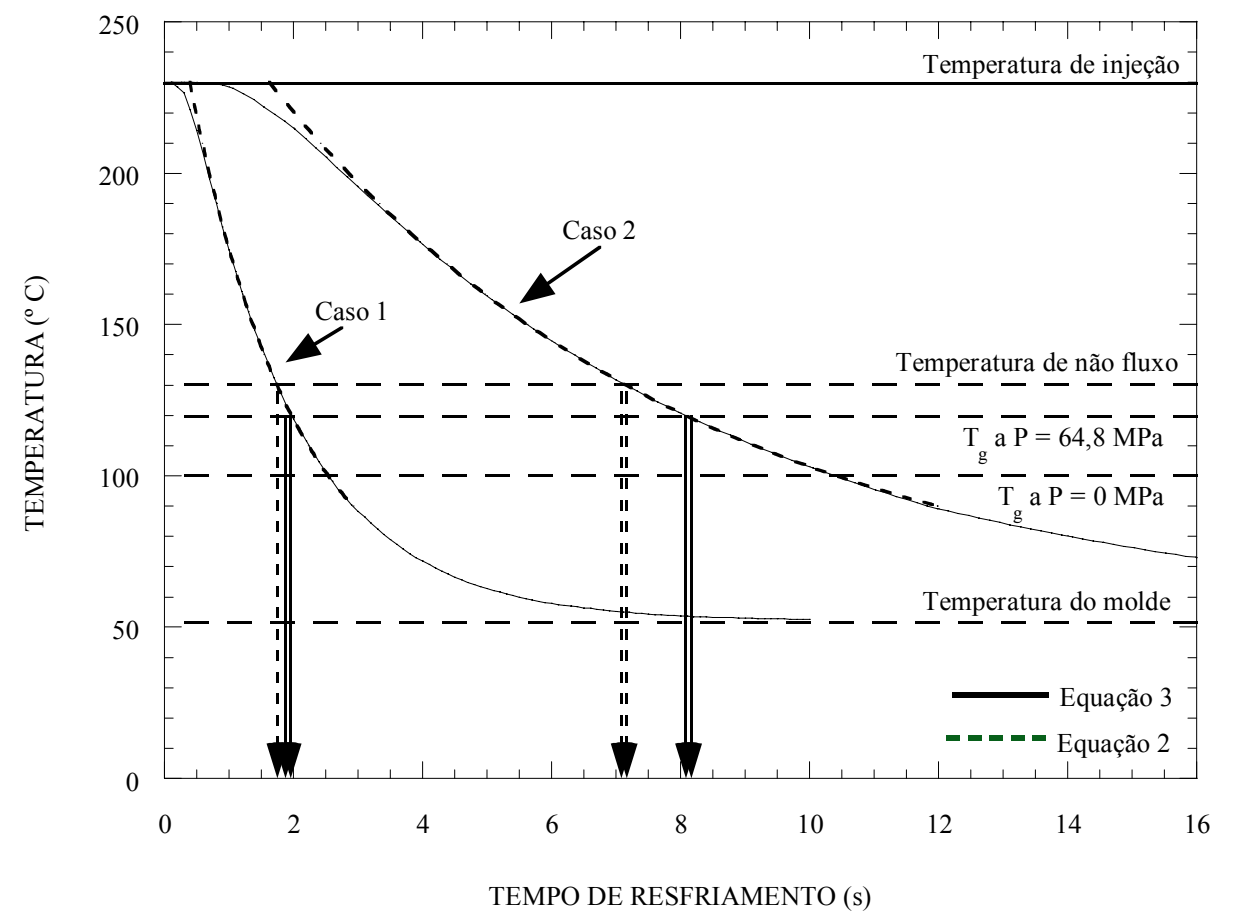

Figura 5: Comparação entre os resultados obtidos para as Equações 1 e 2.

Caso 1: Equação $1 \mathrm{t}=1,74 \mathrm{~s} / \mathrm{t}=1,98 \mathrm{~s}$; Equação $2 \mathrm{t}=1,74 \mathrm{~s} / \mathrm{t}=1,97 \mathrm{~s}$.

Caso 2: Equação $1 \mathrm{t}=7,10 \mathrm{~s} / \mathrm{t}=8,04 \mathrm{~s}$; Equação $2 \mathrm{t}=7,15 \mathrm{~s} / \mathrm{t}=8,08 \mathrm{~s}$. 
Com os resultados obtidos da Equação 3 para o tempo de solidificação, a espessura do corpo de prova e as espessuras dos canais de ataque foram representadas graficamente na Figura 6. Observa-se que existe uma variação exponencial do tempo de solidificação em função da variação da espessura, ou seja, quanto maior a espessura, maior o tempo de solidificação.

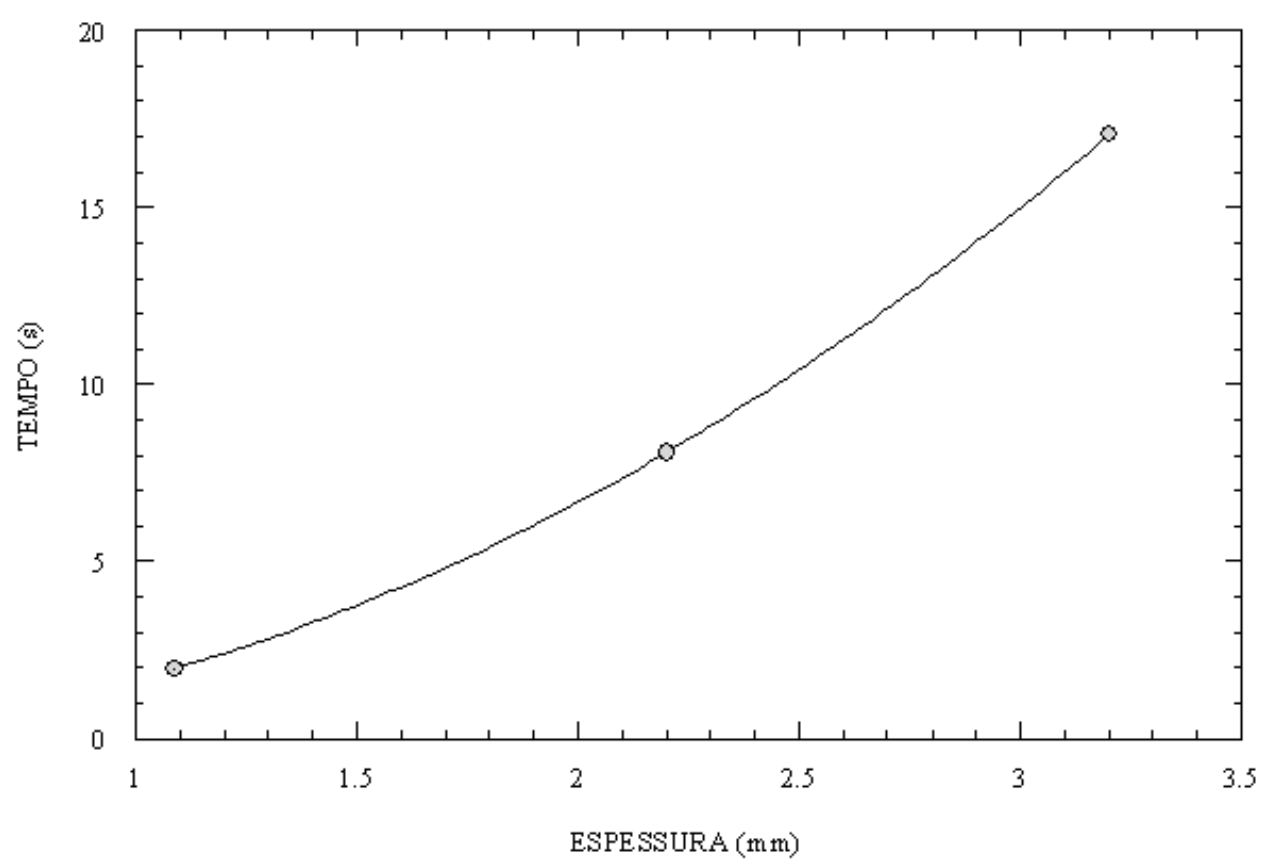

Figura 6: Tempo de solidificação vs Espessura

\section{CONCLUSÃO}

Variando o tempo e a pressão de recalque, foi observado o aumento de massa do corpo de prova injetado. Quando a temperatura do material atingir a temperatura de não-fluxo dentro do canal de ataque, a massa do corpo de prova não será mais alterada. Esta transição foi observada graficamente. A partir de equações, foi possível determinar o tempo de solidificação do canal de ataque e comparar com o tempo em que o corpo de prova não receberá mais material. Os resultados experimentais e os resultados analíticos são coerentes.

\section{AGRADECIMENTOS}

À empresa Macroplast, pelo fornecimento do material polimérico e o incentivo dado a este trabalho pela Faculdade de Tecnologia Senai.

À Universidade do Estado de Santa Catarina - UDESC, por ter disponibilizado os seus equipamentos para o desenvolvimento deste trabalho.

\section{REFERÊNCIAS BIBLIOGRÁFICAS}

[1] DA CRUZ, S., Moldes de Injeção, São Paulo: Ed. Hemus, pp. 75-79.

[2] PROVENZA, F., Moldes para Plásticos, Ed. F. Provenza, pp. 5.105-5.122, 1991.

[3] SORS, L., BARDDÓCZ, L., RADNÓTI, I., Plásticos Moldes \& Matrizes, São Paulo: Ed. Hemus, pp. 144-151.

[4] GLANVILl A.B., DENTON E.N., Princípios Básicos e Projetos. Moldes de Injeção, São Paulo: Edgard Blücher Ltda, 1980. 
[5] BOM, PEDRO R., "Efeito da Pressão e do Tempo de Recalque no Empacotamento de Peças Injetadas", Monografia apresentada para a obtenção do Título de Especialista em Ciência e Engenharia de Materiais no Centro de Ciências Tecnológicas, Universidade do Estado de Santa Catarina, UDESC, pp. 17-24, junho 2002.

[6] HARADA, J., Moldes para Injeção de Termoplásticos, São Paulo: Ed. Artiber, 2004.

[7] DA CRUZ, A.C., "Determinação do Tempo de Solidificação de Peças Termoplásticas Moldadas pelo Processo de Injeção", Dissertação de Mestrado, Ciência e Engenharia de Materiais no Centro de Ciências Tecnológicas, Universidade do Estado de Santa Catarina, UDESC, pp. 93-95, julho 2005.

[8] BOM, PEDRO R., "Efeito da Pressão e do Tempo de Recalque no Empacotamento de Peças Injetadas", Revista Plástico Industrial, São Paulo, pp. 168-181, maio 2002.

[9] DETERRE, R., MOUSSEAU, P., SARDA, A., Injection dês Polymères, Paris: Ed. Tec \& Doc Lavoisier, pp. 57-61, 72-73, 258, 2003.

[10] AgAsSAnt, J.F., AVEnAS, P., SERGENT, J.P., VICENT, M., La Mise em Forme dês Matières Plastiques, 3 ed., Paris: Ed. Tec \& Doc Lavoisier, 1996.

[11] MOLDFLOW, Aplicativo versão 4.1, biblioteca de materiais, SAN, Basf. 